\title{
Targeting mRNA for the treatment of facioscapulohumeral muscular dystrophy
}

\author{
Bo Bao ${ }^{1}$, Rika Maruyama ${ }^{1}$, Toshifumi Yokota ${ }^{1,2, *}$ \\ ${ }^{1}$ Department of Medical Genetics, School of Human Development, Faculty of Medicine and Dentistry, University of Alberta, \\ Edmonton AB, Canada; \\ ${ }^{2}$ Muscular Dystrophy Canada Research Chair, University of Alberta, Edmonton AB, Canada.
}

\begin{abstract}
Summary Facioscapulohumeral muscular dystrophy (FSHD) is an inherited autosomal dominant disorder characterized clinically by progressive muscle degeneration. Currently, no curative treatment for this disorder exists. FSHD patients are managed through physiotherapy to improve function and quality of life. Over the last two decades, FSHD has been better understood as a disease genetically characterized by a pathogenic contraction of a subset of macrosatellite repeats on chromosome 4. Specifically, several studies support an FSHD pathogenesis model involving the aberrant expression of the double homeobox protein 4 (DUX4) gene. Hence, potential therapies revolving around inhibition of $D U X 4$ have been explored. One of the potential treatment options is the use of effective antisense oligonucleotides (AOs) to knockdown expression of the myopathic $D U X 4$ gene and its downstream molecules including paired-like homeodomain transcription factor 1 (PITX1). Success in the suppression of PITX1 expression has already been demonstrated systemically in vivo in recent studies. In this article, we will review the pathogenesis of FSHD and the latest research involving the use of antisense knockdown therapy.
\end{abstract}

Keywords: Antisense oligonucleotide therapy, DUX4, morpholino, gene therapy, PITX1, skeletal muscle

\section{Introduction}

Facioscapulohumeral muscular dystrophy (FSHD) is an autosomal dominant gain-of-function genetic disorder involving asymmetric muscle weakness and atrophy particularly observed in the face, shoulder, upper arms, further extending into the trunk and legs (1). While there are a dozen forms of muscular dystrophy, FSHD is the third most common muscular dystrophy after Duchenne muscular dystrophy (DMD) and myotonic dystrophy, affecting approximately 1 in 8,000 - 20,000 individuals $(2,3)$. However, since an individual can remain asymptomatic or exhibit mild symptoms, the

Released online in J-STAGE as advance publication August 5, 2016.

*Address correspondence to:

Dr. Toshifumi Yokota; Department of Medical Genetics, School of Human Development, Faculty of Medicine and Dentistry, University of Alberta, Edmonton AB, Canada T6G 2H7.

E-mail: toshifum@ualberta.ca frequency of FSHD occurrence could be underestimated. While several candidate genes for FSHD have been identified and explored thus far, the role of DUX4 as the causative gene in the pathogenesis of FSHD has predominated in the literature $(4,5)$. Hence, the inhibition of DUX4 expression and the suppression of its downstream molecules can potentially offer therapeutic benefit. The potential of antisense oligonucleotide (AO) therapy as a therapeutic treatment for neuromuscular diseases has recently been highlighted by several clinical trials involving DMD and spinal muscular atrophy (e.g. ClinicalTrials.gov identifier: NCT02193074). Recently, in vitro studies have demonstrated success in the suppression of DUX4 mRNA expression by administering AOs into primary skeletal muscle cells of FSHD patients (5). Nonetheless, desired progress has been impeded by the lack of FSHD animal models and inefficient uptake of AOs into FSHD skeletal muscle fibers. This article will cover the pathogenesis of FSHD, the applicability of antisense oligonucleotide therapy in FSHD, as well as the limitations of antisense therapy in neuromuscular disorders. 


\section{Pathogenesis of FSHD}

FSHD is a genetic and epigenetic disorder primarily involving skeletal muscles. Unique to FSHD are asymmetric muscle weaknesses particularly seen in the face, shoulder and extremities (1). Typically, the onset of symptoms observed in FSHD patients occurs from 15-30 years of age. Depending on the genetic and epigenetic factors, disease manifestations will differ. Initially, FSHD phenotype involves facial muscle weakness resulting in difficulty with labial consonants, whistling and drinking through a straw (6). Upon progression of the disease, atrophy involving the upper arms, pelvic girdle, and lower limbs will occur. Hence, $10-20 \%$ of FSHD patients will progressively lose independent ambulation and become wheelchair bound by the age of 50 years (7). The most common presenting symptom is shoulder abduction weakness, seen in $82 \%$ of symptomatic patients. Shoulder weakness is the result of a more lateral positioning of the scapula than normal leading to a winged scapula appearance. Additionally, a clinical finding specific to FSHD is the Beevor's sign, which describes the ascending movement of the umbilicus when flexing the neck due to early truncal weakness. Extra-muscular manifestations of FSHD involve high-frequency hearing loss, and retinal telangiectasias in $75 \%$ and $60 \%$ of patients, respectively (8). Factors that contribute to the severity of phenotype include the age of symptom onset and also the extent of genetic changes.

\subsection{Genetics of FSHD}

Several candidate genes have reportedly been involved in the FSHD phenotype described previously: DUX4, FSHD region gene 1 (FRG1), FSHD region gene 2 (FRG2), and adenine nucleotide translocase 1 (ANT1) (9). Recent studies have primarily attributed pathogenesis of FSHD to the aberrant expression of a normally dormant gene, $D U X 4(10)$. DUX4 is a double homeodomain transcription factor encoded within the D4Z4 tandem repeat. In a healthy individual, the subtelomeric region of chromosome $4 \mathrm{q}$ contains 11 100 copies of the $3.3 \mathrm{~kb}$ D4Z4 macrosatellite repeat, each with a copy of DUX4 (11). However, DUX4 is not expressed in normal functioning somatic tissues such as well-differentiated muscles fibers. While $D U X 4$ is expressed in early development, it is transcriptionally silenced during cellular differentiation of somatic tissues by $\mathrm{CpG}$ methylation of D4Z4 repeats (12). In early development, DUX4 may play a role in activating a stem-cell-like transcriptional pathway (10). Expression of DUX4 is maintained in the spermatogonia of the male testis $(13,14)$. While the role of $D U X 4$ in the seminiferous tubule is not clearly defined, it may be involved in germ cell maintenance and development of stem cells (15). Snider et al. illustrated the expression of full-length DUX4 mRNA in induced pluripotent stem cells (iPSCs). However, the aberrant expression of DUX4 is severely toxic to muscle tissues, resulting in oxidative stress and apoptosis (16-19). A recent study indicates that expression of DUX4 in B cells was even capable of generating leukemia in mice in vivo (20). Additionally, DUX4-induced expression of antigenic proteins such as ERV may be involved in the inflammatory response seen in FSHD muscle histopathology, contributing to muscle atrophy (13).

\subsection{Epigenetics of FSHD}

In FSHD patients, several epigenetic changes take place to result in the pathogenic expression of DUX4 in skeletal muscle cells. The first is the contraction of the D4Z4 array. Specifically, the deletion of D4Z4 repeat array in the subtelomeric region of chromosome 4 called 4 q35 to less than 10 units results in reduced methylation and subsequently chromatin remodeling (21). This defect was first described as a reduction seen in EcoRI fragment of genomic DNA as compared to healthy individuals. While healthy individuals possess 11 to 150 D4Z4 repeats with EcoRI fragments being 40-300 kb in size, FSHD patients have between 1 to 10 repeats and EcoRI fragments at $10-38 \mathrm{~kb}$ in size (22). Following reduced DNA methylation due to contracted D4Z4 repeat, a more relaxed chromatin structure allows greater expression of genes located on that locus. The smaller the D4Z4 repeat size, the greater severity of the disease. Secondly, the presence of pLAM1 polyadenylated mRNA site at the distal D4Z4 unit is another condition for disease manifestation $(23,24)$. Interestingly, the polyadenylation site is only intact on chromosome 4qA and not 4qB (25). As such, possible therapeutic strategy for FSHD may include inhibition of polyadenylation in chromosome $4 \mathrm{qA}$ leading to DUX4 gene silencing. Ultimately, the deletion of D4Z4 array leads to a combination of DNA hypomethylation and polyadenylation allowing the aberrant expression of DUX4. Hence, DUX4 are occasionally expressed in skeletal muscle nuclei (14). Detectable levels of DUX4 up-regulation in myoblast was illustrated by Snider et al., where 1 in 1,000 nuclei was positive for DUX4 in proliferating primary FSHD myoblasts. Tassin et al. also confirmed low expression of DUX4 in proliferating FSHD myoblasts via Western blot analysis. The study demonstrated increased DUX4 protein expression within 1 in 200 nuclei after allowing FSHD primary myoblasts to differentiate for 4 days. Hence, DUX4 transcription can be influenced by physiological stage of the cells and its surrounding environment (26).

\subsection{Types of FSHD}

Two types of FSHD exist: FSHD1 and FSHD2. The most common form, FSHD1, occurs in over $95 \%$ of 


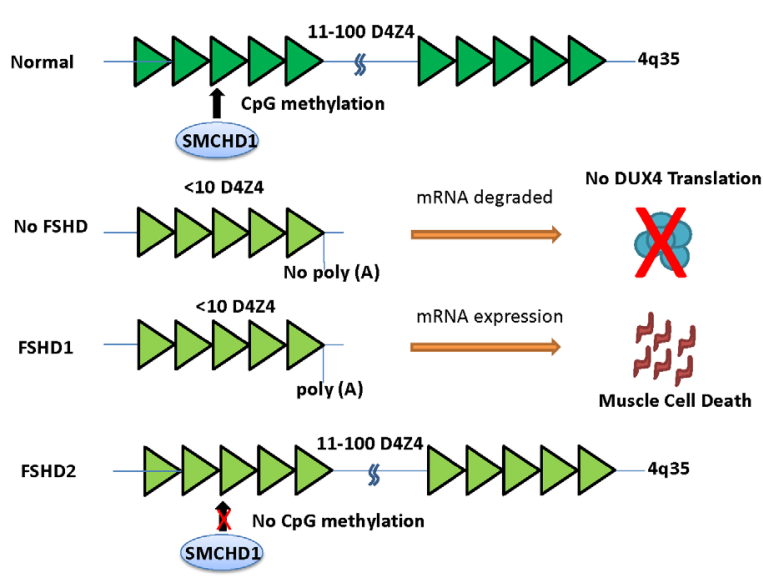

Figure 1. Role of chromosome 4 q35 D4Z4 repeat array in the pathogenesis of facioscapulohumeral muscular dystrophy (FSHD). While contraction of D4Z4 repeats in FSHD1 results in the expression of $D U X 4$ and subsequent myopathy, expression of DUX4 in FSHD2 is due to a mutation in the $S M C H D 1$ gene.

FSHD patients (21). Genetic analysis links FSHD 1 to the genetic contraction of macrosatellite D4Z4 repeat array on chromosome 4. FSHD2, however, has a normal number of D4Z4 repeats and instead involves a heterozygous mutation in the SMCHD1 gene on chromosome 18p, a chromatin modifier (27) (Figure 1). Nonetheless, patients with FSHD1 and FSHD2 share similar clinical presentations. Over the last two decades, progress has been made in the better understanding of the pathogenesis of FSHD, potentially leading to therapeutic strategies for the treatment of FSHD.

\section{Therapeutic Approaches to FSHD}

No definitive curative treatment for FSHD has been established despite the recent progress made in understanding the genetic and pathophysiologic mechanism of the disease. Current standard clinical management options include physical therapy, aerobic exercise, respiratory function therapy, and orthopedic intervention $(28,29)$. The current guideline for the management of individuals with FSHD is based on a principle of improving function and quality of life. Current drug therapy trials for the management of FSHD include myostatin inhibitor luspatercept and anti-inflammatory biologics (ATYR1940). The basis for anti-inflammatory biologics is to suppress inflammation commonly seen in muscle pathology of FSHD patients in order to slow phenotype progression. All the while, gene therapy has been explored to reduce pathogenic DUX4 protein production in FSHD by controlling D4Z4 methylation, suppressing DUX4 mRNA, and inhibiting DUX4 pathway $(5,17,30-32)$. Several inhibitory tools are available for use including small interfering RNA (siRNA), small hairpin RNA (shRNA), microRNA (miRNA) and antisense oligonucleotides (33,34).

\subsection{RNA interference}

RNA interference-based approach has been explored by several studies as a prospective treatment for FSHD. siRNA are small double-stranded RNA molecules that act in the cytoplasm of cells to silence mRNA of targeted gene via a process of transcript degradation or translational inhibition (35). siRNA has been used to target the 3' untranslated region transcribed from pLAM (5). While shRNA (or artificial miRNA) shares a similar process of silencing target genes as siRNA, it acts on the nucleus of the cell instead. Hence, the advantage of shRNA lies in its ability to have long lasting effects at low doses. Wallace et al. have demonstrated in vivo success with an artificial miRNA by delivering miDUX4 through adeno-associated viral (AAV) vector into an AAV-based DUX4 mouse model (32). The study illustrates a $90 \%$ reduction in DUX4 protein and $64 \%$ reduction in DUX4 mRNA. One of the limitations of RNA interference approach is its high dose cytotoxicity derived from its off-target effects $(36,37)$. Additionally, the negative charge, size, and rigid structure of siRNA can complicate its passive diffusion across the target cell. Therefore, they require viral vectors for in vivo systemic delivery, which can cause significant side effects such as immune response.

\subsection{Antisense oligonucleotides}

Antisense oligonucleotides (AOs) on the other hand are small single-stranded DNA-like molecules of 8 to 30 base pairs in length which can be chemically modified specifically to interfere with mRNA processing and stability (38). AOs can either act via exon skipping, splice modulation, or inhibition of gene expression. Importantly they do not require viral vectors for in vivo systemic delivery. The potential of AOs was initially demonstrated following discovery that transfection of short DNA sequence can inhibit gene expression (39). Currently, antisense therapy is used in preclinical studies and clinical trials of a variety of neuromuscular disorders including DMD, spinal muscular atrophy (SMA), and Fukuyama congenital muscular dystrophy (FCMD) (40-46). Currently, Sarepta therapeutics, Nippon-Shinyaku, and Prosensa are conducting clinical trials involving phosphorodiamidate morpholino oligomer (PMO) and 2'O methyl phosphorothioate oligonucleotide (2'OMePS). Beyond neuromuscular disease, antisense-mediated gene suppression therapy has taken ground in a spectrum of disease including cancer, thrombosis, and Ebola (47-50).

\section{Antisense oligonucleotide therapy for FSHD}

In light of recent success antisense therapy has in the study of neuromuscular disorders, its application to FSHD has been investigated in multiple studies (51). 
Antisense therapy uses antisense oligonucleotides (AOs) which are short single-stranded DNA-like molecules to selectively hybridize pre-mRNA via base pairing (38). Since oligonucleotides have difficulty penetrating the lipid bilayer of cells and are also degradable by nucleases, several AO chemistries have been designed to continuously improve efficacy including PMO, octaguanidine dendrimer conjugated PMOs (vPMO), and peptide-phosphorodiamidate morpholino oligomer (PPMO). Challengingly, the DUX4 open reading frame (ORF) is located in the first exon and hence makes disruption of its reading frame by antisensemediated exon skipping difficult (52). However, effective interference of DUX4 mRNA using antisense oligonucleotide has been illustrated by Vanderplanck et al. in vitro (5). The study utilizes 2 'OMePs to target splice sites of exon 2 and 3 and thereby disrupts the polyadenylation signal at the 3'UTR. Upon Western blot analysis, no DUX4 protein can be detected following treatment with $600 \mathrm{nM}$ of AOs. As well, the 2 'OMePs administered was able to achieve $50 \%$ reduction in the intensity of $D U X 4$ gene upon RT-PCR analysis of DUX4 gene fragments. However, the 2'OMePs chemistry developed by Prosensa targeting DMD has recently failed phase III clinical trial due to its toxicity and ineffectiveness $(53,54)$.

\subsection{Phosphorodiamidate morpholino oligomer (PMO)}

PMO is one of the most commonly used modified AO chemistry to offer sequence-specific inhibition of gene expression (55). PMO consists of short chains of 2030 nucleic acid bases, a morpholino ring and a nonionic phosphorodiamidate intersubunit linkage (56). Its structural chemistry provides high nuclease resistance, high affinity to target RNA, resistance to metabolic degradation, and reduced activation of toll-like receptors $(57,58)$. The phosphorodiamidate backbone, in particular, helps the morpholino evade targeting by nucleases. The modified backbone also provides additional stability by helping the molecule evade immune responses. As well, compared to equivalent DNA-based antisense oligonucleotides, morpholino also has a higher binding affinity $(56,57,59)$. Hence, morpholinos lead to less off-target effects. In addition, morpholinos have longer effective half-life due to its substitution for a six-membered morpholine ring. In vivo DMD studies have shown the efficacy of PMO by illustrating its ability to penetrate dysfunctional muscle fibers, increase dystrophin expression and ultimately improve muscle function (60-63). Marsollier et al. have shown the efficacy of transfecting PMO in immortalized FSHD cells to target $D U X 4$ mRNA polyadenylation signal in order to suppress the expression of DUX4. One of the challenges in building a therapeutic strategy around PMOs is its difficulty in crossing the lipid bilayer of cells and thereby resulting in reduced delivery to skeletal muscles (38). While the leaky muscle membrane of DMD assists in the uptake of AOs into a target cell, FSHD myofibers lack this leakiness (64-66). Hence, to achieve and maintain therapeutic efficacy, PMOs may need to be administered in large and repeated doses. However, a higher dose could result in harmful effects.

\subsection{Octa-guanidine dendrimer-conjugated vivo- morpholinos (vPMO)}

In order to improve the cell-penetrating ability of antisense oligonucleotides, second-generation oligonucleotide such as octa-guanidine dendrimerconjugated vivo-morpholinos (vPMO) have been used. Vivo-morpholinos essentially conjugates with a triazine core scaffold of eight guanidinium head groups to help penetrate the cell membrane and improve delivery of the morpholino (66-68) (Figure 2). The positive charge that accompanies $\mathrm{PPMO}$ assist in uptake and competes with splicing factors. In vivo studies with vPMO carried out by Yokota et al. have demonstrated greater efficacy in inducing exon 6-9 multiple exon skipping in dystrophic dogs compared to unconjugated PMO. In addition, no vPMO toxicity has been recorded upon systemic injection into mice up to $12 \mathrm{mg} / \mathrm{kg}$ (69). However, the positive charge does increase the risk of blood clot formation (70).

\subsection{Peptide-conjugated phosphorodiamidate morpholino oligomer (PPMO)}

Another candidate antisense oligonucleotide that has improved delivery efficacy while also minimizing toxicity is peptide-conjugated phosphorodiamidate morpholino oligomer (PPMO). Multiple peptideconjugated oligonucleotide derivatives have been explored in recent studies, including arginine-rich peptide B-peptide, Pip-5e, Pip-6 and Pip6a (71-74). In particular, the newest modification, Pip-6a demonstrates improved stability and cardiac muscle penetration (71). Recent studies involving administration of PPMO into the $m d x$ mouse model of DMD have shown promising results characterized by restored dystrophin at low doses, increased uptake and prolonged functionality (65,74-77). Specifically, an intramuscular injection of $2 \mu \mathrm{g}$ of PPMO resulted in $85 \%$ dystrophin-positive fiber expression compared to only $14 \%$ observed in PMO treatment (65). Similarly, $>95 \%$ of exonskipped RNA transcript was observed after IV injection of $20 \mathrm{mg} / \mathrm{kg}$ PPMO. Additionally, functional improvements were observed in various skeletal muscles after administration of PPMO (75). The improved effectiveness of PPMO compared to PMO is attributable to its active uptake process involving caveolae-mediated endocytosis (71). While access to the target cell has improved over the years, challenges 


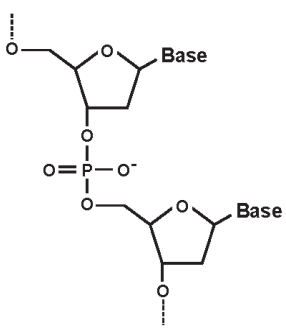

DNA

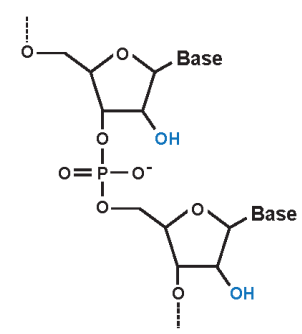

RNA

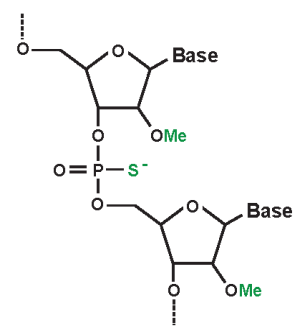

2' OMePS<smiles>COCC1CN(P(=O)(O)OC2CN(C)C[C@H](C)O2)C[C@@H](C)O1</smiles>

Morpholino (unmodified)

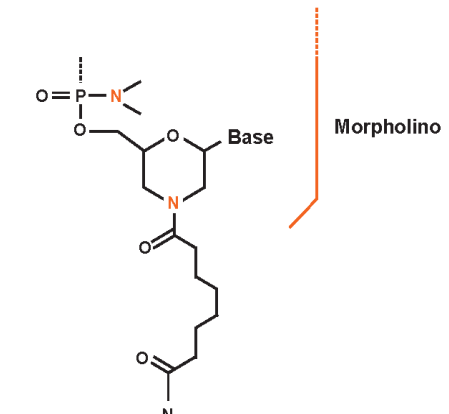

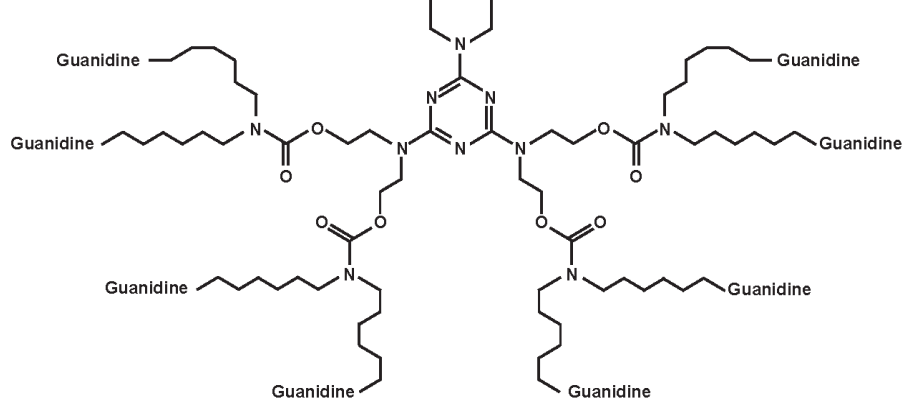

Vivo-Morpholino

Figure 2. Molecular structure of various antisense oligonucleotide chemistries derived over the years. New generations of antisense chemistries such as 2'O-methylated antisense oligonucleotides (2'OMePS) and octa-guanidine dendrimer conjugated PMOs (vPMO) are artificially modified to improve delivery into target cells.

remain in promoting the internal distribution of PMO to the nucleus for it to be active (65). Most of the PPMO are nonetheless distributed in the cytoplasm away from its site of action. As well, the toxicity of PPMO remains a challenge. PPMO however, benefits from its low therapeutic dose and sustained effects on the target cell. An ideal oligonucleotide therapy will be one that demonstrates long-term effects, sufficient efficacy at a low dose, and low toxicity.

\section{AO-based therapy targeting PITXI}

Since the aberrant expression of $D U X 4$, a transcription factor, can lead to pathogenic deregulation of multiple genes in muscle, targeting of a downstream gene regulated by $D U X 4$ has also been explored recently. PITX1, a homeobox transcription factor, is a direct transcriptional target of DUX4 (24). PITX1 has previously been illustrated to be elevated in muscle fibers of FSHD patients and is understood to be involved in the myopathy characterized in FSHD. Studies have found that the PITX1 gene is 10-20 times up-regulated in the muscle fibers of FSHD patients. The role of PITXI in myopathy was shown in vivo via a tet-repressible muscle-specific PITX1 transgenic mouse model $(78,79)$. The PITX1 transgenic mouse model with overexpression of PITX1 in skeletal muscles demonstrates a similar disease phenotype to the muscular dystrophy seen in FSHD patients. Specifically, mice with over-expressed PITXI display reduced muscle fiber size and muscle strength. Hence, up-regulation of PITX1 via DUX4 overexpression contributes to the atrophy and wasting of skeletal muscles in FSHD patients. All in all, the downstream molecular changes due to ectopic DUX4 expression are cytotoxic. Padley et al. have also illustrated the feasibility of suppressing PITX1 using morpholinos in vivo (78). The study involves administration of $10 \mathrm{mg} /$ $\mathrm{kg}$ of vPMOs into a tet-repressible muscle-specific PITX1 overexpressing transgenic mouse model for 6 
weeks. The vPMOs is used to inhibit the translation of PITX1 by targeting the 25 base sequence at the translation start site of the PITX1 mRNA transcript (78). Immunochemistry results illustrated $70 \%$ reduction in PITX1 expression in triceps and $60 \%$ expression reduction in quadriceps. Muscle pathology results also illustrated a reduction in PITX1 positive nuclei in muscle fibers as evidenced by $44 \%$ reduction in the number of angular shaped atrophic myofibers seen. Antisense targeting of the PITXI gene involved in myopathy is, therefore, an efficient therapeutic strategy for FSHD.

\section{FSHD animal model}

Despite advances in the design of oligonucleotide chemistry to promote increased uptake and efficacy, we still lack an adequate FSHD animal model to evaluate functional benefit and toxicity of antisense therapy. Namely, DUX4 transgenic mouse model has not been able to capture the full disease phenotype of FSHD. For instance, the D4Z4-2.5 mice have normal histology of the limb, grip strength and creatine kinase $(12,17)$. The challenge in generating a proper animal model for FSHD stems from the fact that D4Z4 macrosatellite encoding DUX4 is unique to primates (80). Hence, introducing $D U X 4$ expression into natural laboratory models will be challenging. Currently, the best available system for in vivo study is the AAV-model developed by Wallace et al., which demonstrates myopathy consistent with FSHD. The model is established by using adeno-associated viral vectors to deliver DUX4 into mouse muscle fibers (34). Successful establishment of an FSHD animal model based on DUX4 expression will assist in the understanding of the pathogenesis of disease and development of therapeutic approaches for FSHD.

\section{Conclusion}

Over the last two decades, progress has been made in our understanding of FSHD pathogenesis. As a gain-offunction disease characterized by the aberrant expression of $D U X 4$, a knock-down approach involving antisense oligonucleotide has been explored. In particular, AOs have been especially useful by selectively inhibiting translation of target mRNA. Application of antisense oligonucleotide in the treatment of neuromuscular disorder has progressed in recent years, and its potential benefit has been observed from in vitro studies demonstrating successful suppression of DUX4 expression. Additionally, promising benefits have been observed in the treatment of transgenic mouse model expressing PITX1 with AOs. With the advancement of modified oligonucleotides providing enhanced delivery and increased efficacy, the movement towards gene therapy seems plausible.

\section{Acknowledgements}

T Yokota has been funded by Canada Foundation for Innovation (CFI), Muscular Dystrophy Canada, The Friends of Garrett Cumming Research Fund, HM Toupin Neurological Research Fund, Canadian Institutes of Health Research (CIHR), National Institutes of Health (NIH), Women and Children's Health Research Institute (WCHRI), Slipchuk SMA Research Fund, Jesse's Journey, Alberta Enterprise and Advanced Education, and University of Alberta. The authors have no other relevant affiliations or financial involvement with any organization or entity with a financial interest in or financial conflict with the subject matter or materials discussed in the manuscript. This includes employment, consultancies, honoraria, stock ownership or options, expert testimony, grants or patents received or pending, or royalties.

\section{References}

1. Mul K, Lassche S, Voermans NC, Padberg GW, Horlings CG, van Engelen BG. What's in a name? The clinical features of facioscapulohumeral muscular dystrophy. Pract Neurol. 2016; 16:201-207.

2. Deenen JC, Arnts H, van der Maarel SM, Padberg GW, Verschuuren JJ, Bakker E, Weinreich SS, Verbeek AL, van Engelen BG. Population-based incidence and prevalence of facioscapulohumeral dystrophy. Neurology. 2014; 83:1056-1059.

3. Mostacciuolo ML, Pastorello E, Vazza G, Miorin M, Angelini C, Tomelleri G, Galluzzi G, Trevisan CP. Facioscapulohumeral muscular dystrophy: Epidemiological and molecular study in a north-east Italian population sample. Clin Genet. 2009; 75:550-555.

4. Gabriels J, Beckers MC, Ding H, De Vriese A, Plaisance S, van der Maarel SM, Padberg GW, Frants RR, Hewitt JE, Collen D, Belayew A. Nucleotide sequence of the partially deleted D4Z4 locus in a patient with FSHD identifies a putative gene within each $3.3 \mathrm{~kb}$ element. Gene. 1999; 236:25-32.

5. Vanderplanck C, Ansseau E, Charron S, Stricwant N, Tassin A, Laoudj-Chenivesse D, Wilton SD, Coppee F, Belayew A. The FSHD atrophic myotube phenotype is caused by DUX4 expression. PloS One. 2011; 6:e26820.

6. Wang LH, Tawil R. Facioscapulohumeral Dystrophy. Curr Neurol Neurosci Rep. 2016; 16:66.

7. Statland JM, Tawil R. Risk of functional impairment in Facioscapulohumeral muscular dystrophy. Muscle Nerve. 2014; 49:520-527.

8. Kan HE, Janssen BH, Voet NBM. Facioscapulohumeral Dystrophy. In: Neuromuscular Imaging (Mike P, Wattjes DF, eds.). Springer, New York, USA, 2013; pp. 295-304.

9. Gabellini D, D'Antona G, Moggio M, Prelle A, Zecca C, Adami R, Angeletti B, Ciscato P, Pellegrino MA, Bottinelli R, Green MR, Tupler R. Facioscapulohumeral muscular dystrophy in mice overexpressing FRG1. Nature. 2006; 439:973-977.

10. Tawil R, van der Maarel SM, Tapscott SJ. Facioscapulohumeral dystrophy: The path to consensus on pathophysiology. Skelet Muscle. 2014; 4:12.

11. van der Maarel SM, Frants RR. The D4Z4 repeat- 
mediated pathogenesis of facioscapulohumeral muscular dystrophy. Am J Hum Genet. 2005; 76:375-386.

12. Krom YD, Thijssen PE, Young JM, et al. Intrinsic epigenetic regulation of the D4Z4 macrosatellite repeat in a transgenic mouse model for FSHD. PLoS genet. 2013; 9:e1003415.

13. Young JM, Whiddon JL, Yao Z, Kasinathan B, Snider L, Geng LN, Balog J, Tawil R, van der Maarel SM, Tapscott SJ. DUX4 binding to retroelements creates promoters that are active in FSHD muscle and testis. PLoS genet. 2013; 9:e1003947.

14. Snider L, Geng LN, Lemmers RJ, Kyba M, Ware CB, Nelson AM, Tawil R, Filippova GN, van der Maarel SM, Tapscott SJ, Miller DG. Facioscapulohumeral dystrophy: incomplete suppression of a retrotransposed gene. PLoS genet. 2010; 6:e1001181.

15. Geng LN, Yao Z, Snider L, Fong AP, Cech JN, Young JM, van der Maarel SM, Ruzzo WL, Gentleman RC, Tawil R, Tapscott SJ. DUX4 activates germline genes, retroelements, and immune mediators: Implications for facioscapulohumeral dystrophy. Dev Cell. 2012; 22:3851.

16. Bosnakovski D, Lamb S, Simsek T, Xu Z, Belayew A, Perlingeiro R, Kyba M. DUX4c, an FSHD candidate gene, interferes with myogenic regulators and abolishes myoblast differentiation. Exp Neurol. 2008; 214:87-96.

17. Bosnakovski D, Xu Z, Gang EJ, Galindo CL, Liu M, Simsek T, Garner HR, Agha-Mohammadi S, Tassin A, Coppee F, Belayew A, Perlingeiro RR, Kyba M. An isogenetic myoblast expression screen identifies DUX4mediated FSHD-associated molecular pathologies. The EMBO J. 2008; 27:2766-2779.

18. Kowaljow V, Marcowycz A, Ansseau E, et al. The DUX4 gene at the FSHD1A locus encodes a pro-apoptotic protein. Neuromuscul Disord. 2007; 17:611-623.

19. Snider L, Asawachaicharn A, Tyler AE, Geng LN, Petek LM, Maves L, Miller DG, Lemmers RJ, Winokur ST, Tawil R, van der Maarel SM, Filippova GN, Tapscott SJ. RNA transcripts, miRNA-sized fragments and proteins produced from D4Z4 units: New candidates for the pathophysiology of facioscapulohumeral dystrophy. Hum Mol Genet. 2009; 18:2414-2430.

20. Yasuda T, Tsuzuki S, Kawazu M, et al. Recurrent DUX4 fusions in B cell acute lymphoblastic leukemia of adolescents and young adults. Nature genet. 2016; 48:569-574.

21. Wijmenga C, Hewitt JE, Sandkuijl LA, Clark LN, Wright TJ, Dauwerse HG, Gruter AM, Hofker MH, Moerer P, Williamson R. Chromosome 4q DNA rearrangements associated with facioscapulohumeral muscular dystrophy. Nature genet. 1992; 2:26-30.

22. Upadhyaya M, Maynard J, Rogers MT, Lunt PW, Jardine P, Ravine D, Harper PS. Improved molecular diagnosis of facioscapulohumeral muscular dystrophy (FSHD): Validation of the differential double digestion for FSHD. J Med Genet. 1997; 34:476-479.

23. Lemmers RJ, van der Vliet PJ, Klooster R, et al. A unifying genetic model for facioscapulohumeral muscular dystrophy. Science. 2010; 329:1650-1653.

24. Dixit M, Ansseau E, Tassin A, et al. DUX4, a candidate gene of facioscapulohumeral muscular dystrophy, encodes a transcriptional activator of PITX1. Proc Natl Acad Sci U S A. 2007; 104:18157-18162.

25. Lemmers RJ, Wohlgemuth M, van der Gaag KJ, van der Vliet PJ, van Teijlingen CM, de Knijff P, Padberg
GW, Frants RR, van der Maarel SM. Specific sequence variations within the $4 \mathrm{q} 35$ region are associated with facioscapulohumeral muscular dystrophy. Am J Hum Genet. 2007; 81:884-894.

26. Pandey SN, Khawaja H, Chen YW. Culture conditions affect expression of DUX4 in FSHD Myoblasts. Molecules. 2015; 20:8304-8315.

27. Lemmers RJ, Tawil R, Petek LM, et al. Digenic inheritance of an SMCHD1 mutation and an FSHDpermissive $D 4 Z 4$ allele causes facioscapulohumeral muscular dystrophy type 2. Nature genet. 2012; 44:13701374.

28. Attarian S, Salort-Campana E, Nguyen K, Behin A, Andoni Urtizberea J. Recommendations for the management of facioscapulohumeral muscular dystrophy in 2011. Rev Neurol (Paris). 2012; 168:910-918.

29. Tawil R, Kissel JT, Heatwole C, Pandya S, Gronseth G, Benatar M, Guideline Development D, Implementation Subcommittee of the American Academy of N, Practice Issues Review Panel of the American Association of $\mathrm{N}$, Electrodiagnostic M. Evidence-based guideline summary: Evaluation, diagnosis, and management of facioscapulohumeral muscular dystrophy: Report of the Guideline Development, Dissemination, and Implementation Subcommittee of the American Academy of Neurology and the Practice Issues Review Panel of the American Association of Neuromuscular \& Electrodiagnostic Medicine. Neurology. 2015; 85:357364.

30. Bosnakovski D, Choi SH, Strasser JM, Toso EA, Walters MA, Kyba M. High-throughput screening identifies inhibitors of DUX4-induced myoblast toxicity. Skelet Muscle. 2014; 4:4.

31. Rival-Gervier S, Lo MY, Khattak S, Pasceri P, Lorincz $\mathrm{MC}$, Ellis J. Kinetics and epigenetics of retroviral silencing in mouse embryonic stem cells defined by deletion of the D4Z4 element. Mol Ther. 2013; 21:15361550.

32. Wallace LM, Liu J, Domire JS, Garwick-Coppens SE, Guckes SM, Mendell JR, Flanigan KM, Harper SQ. RNA interference inhibits $D U X 4$-induced muscle toxicity in vivo: implications for a targeted FSHD therapy. Mol Ther. 2012; 20:1417-1423.

33. Bortolanza S, Nonis A, Sanvito F, Maciotta S, Sitia G, Wei J, Torrente Y, Di Serio C, Chamberlain JR, Gabellini D. AAV6-mediated systemic shRNA delivery reverses disease in a mouse model of facioscapulohumeral muscular dystrophy. Mol Ther. 2011; 19:2055-2064.

34. Wallace LM, Garwick-Coppens SE, Tupler R, Harper SQ. RNA interference improves myopathic phenotypes in mice over-expressing FSHD region gene 1 (FRG1). Mol Ther. 2011; 19:2048-2054.

35. Meister G, Tuschl T. Mechanisms of gene silencing by double-stranded RNA. Nature. 2004; 431:343-349.

36. McBride JL, Boudreau RL, Harper SQ, Staber PD, Monteys AM, Martins I, Gilmore BL, Burstein H, Peluso RW, Polisky B, Carter BJ, Davidson BL. Artificial miRNAs mitigate shRNA-mediated toxicity in the brain: Implications for the therapeutic development of RNAi. Proc Natl Acad Sci U S A. 2008; 105:5868-5873.

37. Grimm D, Streetz KL, Jopling CL, Storm TA, Pandey K, Davis CR, Marion P, Salazar F, Kay MA. Fatality in mice due to oversaturation of cellular microRNA/short hairpin RNA pathways. Nature. 2006; 441:537-541.

38. Touznik A, Lee JJ, Yokota T. New developments in 
exon skipping and splice modulation therapies for neuromuscular diseases. Expert Opin Biol Ther. 2014; 14:809-819.

39. Stephenson ML, Zamecnik PC. Inhibition of Rous sarcoma viral RNA translation by a specific oligodeoxyribonucleotide. Proc Natl Acad Sci U S A. 1978; 75:285-288.

40. Taniguchi-Ikeda M, Kobayashi K, Kanagawa M, Yu CC, Mori K, Oda T, Kuga A, Kurahashi H, Akman HO, DiMauro S, Kaji R, Yokota T, Takeda S, Toda T. Pathogenic exon-trapping by SVA retrotransposon and rescue in Fukuyama muscular dystrophy. Nature. 2011; 478:127-131.

41. Wirth B, Barkats M, Martinat C, Sendtner M, Gillingwater TH. Moving towards treatments for spinal muscular atrophy: hopes and limits. Expert Opin Emerg Drugs. 2015; 20:353-356.

42. Kaczmarek A, Schneider S, Wirth B, Riessland M. Investigational therapies for the treatment of spinal muscular atrophy. Expert Opin Investig Drugs. 2015; 24:867-881

43. Mitrpant C, Porensky P, Zhou H, Price L, Muntoni F, Fletcher S, Wilton SD, Burghes AH. Improved antisense oligonucleotide design to suppress aberrant SMN2 gene transcript processing: towards a treatment for spinal muscular atrophy. PloS One. 2013; 8:e62114.

44. Zhou H, Janghra N, Mitrpant C, Dickinson RL, Anthony K, Price L, Eperon IC, Wilton SD, Morgan J, Muntoni F. A novel morpholino oligomer targeting ISS-N1 improves rescue of severe spinal muscular atrophy transgenic mice. Hum Gene Ther. 2013; 24:331-342.

45. Rigo F, Hua Y, Krainer AR, Bennett CF. Antisense-based therapy for the treatment of spinal muscular atrophy. J Cell Biol. 2012; 199:21-25.

46. Hua Y, Sahashi K, Rigo F, Hung G, Horev G, Bennett $\mathrm{CF}$, Krainer AR. Peripheral SMN restoration is essential for long-term rescue of a severe spinal muscular atrophy mouse model. Nature. 2011; 478:123-126.

47. Heald AE, Iversen PL, Saoud JB, Sazani P, Charleston JS, Axtelle T, Wong M, Smith WB, Vutikullird A, Kaye E. Safety and pharmacokinetic profiles of phosphorodiamidate morpholino oligomers with activity against ebola virus and marburg virus: results of two single-ascending-dose studies. Antimicrob Agents Chemother. 2014; 58:6639-6647.

48. Swenson DL, Warfield KL, Warren TK, Lovejoy C, Hassinger JN, Ruthel G, Blouch RE, Moulton HM, Weller DD, Iversen PL, Bavari S. Chemical modifications of antisense morpholino oligomers enhance their efficacy against Ebola virus infection. Antimicrob Agents Chemother. 2009; 53:2089-2099.

49. Ma W, Lin Y, Xuan W, Iversen PL, Smith LJ, Benchimol $\mathrm{S}$. Inhibition of $\mathrm{p} 53$ expression by peptide-conjugated phosphorodiamidate morpholino oligomers sensitizes human cancer cells to chemotherapeutic drugs. Oncogene. 2012; 31:1024-1033.

50. Buller HR, Gailani D, Weitz JI. Factor XI antisense oligonucleotide for venous thrombosis. N Engl J Med. 2015; 372:1672.

51. Bao B, Yokota T. Potential of antisense therapy for facioscapulohumeral muscular dystrophy. Expert Opin Orphan Drugs. 2015; 3:1365-1374.

52. Ansseau E, Domire JS, Wallace LM, Eidahl JO, Guckes SM, Giesige CR, Pyne NK, Belayew A, Harper SQ. Aberrant splicing in transgenes containing introns, exons, and V5 epitopes: lessons from developing an FSHD mouse model expressing a D4Z4 repeat with flanking genomic sequences. PLoS One. 2015; 10:e0118813.

53. Hoffman E. A rebirth for drisapersen in Duchenne muscular dystrophy? Lancet Neurol. 2014; 13:963-965.

54. Lu QL, Cirak S, Partridge T. What can we learn from clinical trials of exon skipping for DMD? Mol Ther Nucleic Acids. 2014; 3:e152.

55. Taylor MF, Paulauskis JD, Weller DD, Kobzik L. In vitro efficacy of morpholino-modified antisense oligomers directed against tumor necrosis factor-alpha mRNA. J Biol Chem. 1996; 271:17445-17452.

56. Summerton J, Stein D, Huang SB, Matthews P, Weller D, Partridge M. Morpholino and phosphorothioate antisense oligomers compared in cell-free and in-cell systems. Antisense Nucleic Acid Drug Dev. 1997; 7:63-70.

57. Summerton J, Weller D. Morpholino antisense oligomers: Design, preparation, and properties. Antisense Nucleic Acid Drug Dev. 1997; 7:187-195.

58. Hudziak RM, Barofsky E, Barofsky DF, Weller DL, Huang SB, Weller DD. Resistance of morpholino phosphorodiamidate oligomers to enzymatic degradation. Antisense Nucleic Acid Drug Dev. 1996; 6:267-272.

59. Eisen JS, Smith JC. Controlling morpholino experiments: don't stop making antisense. Development. 2008; 135:1735-1743.

60. Yokota T, Duddy W, Partridge T. Optimizing exon skipping therapies for DMD. Acta Myol. 2007; 26:179184.

61. Vitiello L, Bassi N, Campagnolo P, Zaccariotto E, Occhi G, Malerba A, Pigozzo S, Reggiani C, Ausoni S, Zaglia $\mathrm{T}$, Gamba P, Baroni MD, Ditadi AP. In vivo delivery of naked antisense oligos in aged mdx mice: Analysis of dystrophin restoration in skeletal and cardiac muscle. Neuromuscul Disord. 2008; 18:597-605.

62. Yokota T, Lu QL, Partridge T, Kobayashi M, Nakamura A, Takeda S, Hoffman E. Efficacy of systemic morpholino exon-skipping in Duchenne dystrophy dogs. Ann Neurol. 2009; 65:667-676.

63. Malerba A, Thorogood FC, Dickson G, Graham IR. Dosing regimen has a significant impact on the efficiency of morpholino oligomer-induced exon skipping in $\mathrm{mdx}$ mice. Hum Gene Ther. 2009; 20:955-965.

64. Aoki Y, Nagata T, Yokota T, Nakamura A, Wood MJ, Partridge T, Takeda S. Highly efficient in vivo delivery of PMO into regenerating myotubes and rescue in lamininalpha2 chain-null congenital muscular dystrophy mice. Hum Mol Genet. 2013; 22:4914-4928.

65. Moulton HM, Moulton JD. Morpholinos and their peptide conjugates: Therapeutic promise and challenge for Duchenne muscular dystrophy. Biochim Biophys Acta. 2010; 1798:2296-2303.

66. Hoffman EP, Bronson A, Levin AA, Takeda S, Yokota T, Baudy AR, Connor EM. Restoring dystrophin expression in duchenne muscular dystrophy muscle progress in exon skipping and stop codon read through. Am J Pathol. 2011; 179:12-22.

67. Reissner KJ, Sartor GC, Vazey EM, Dunn TE, AstonJones G, Kalivas PW. Use of vivo-morpholinos for control of protein expression in the adult rat brain. $\mathrm{J}$ Neurosci Methods. 2012; 203:354-360.

68. Yokota T, Nakamura A, Nagata T, Saito T, Kobayashi M, Aoki Y, Echigoya Y, Partridge T, Hoffman EP, Takeda $\mathrm{S}$. Extensive and prolonged restoration of dystrophin expression with vivo-morpholino-mediated multiple exon 
skipping in dystrophic dogs. Nucleic Acid Ther. 2012; 22:306-315.

69. Wu B, Li Y, Morcos PA, Doran TJ, Lu P, Lu QL. Octaguanidine morpholino restores dystrophin expression in cardiac and skeletal muscles and ameliorates pathology in dystrophic mdx mice. Mol Ther. 2009; 17:864-871.

70. Ferguson DP, Dangott LJ, Lightfoot JT. Lessons learned from vivo-morpholinos: How to avoid vivo-morpholino toxicity. Biotechniques. 2014; 56:251-256.

71. Lehto T, Castillo Alvarez A, Gauck S, Gait MJ, Coursindel T, Wood MJ, Lebleu B, Boisguerin P. Cellular trafficking determines the exon skipping activity of Pip6a-PMO in mdx skeletal and cardiac muscle cells. Nucleic Acids Res. 2014; 42:3207-3217.

72. Betts C, Saleh AF, Arzumanov AA, Hammond SM, Godfrey C, Coursindel T, Gait MJ, Wood MJ. Pip6-PMO, A new generation of peptide-oligonucleotide conjugates with improved cardiac exon skipping activity for DMD treatment. Mol Ther Nucleic Acids. 2012; 1:e38.

73. Yin H, Saleh AF, Betts C, Camelliti P, Seow Y, Ashraf S, Arzumanov A, Hammond S, Merritt T, Gait MJ, Wood MJ. Pip5 transduction peptides direct high efficiency oligonucleotide-mediated dystrophin exon skipping in heart and phenotypic correction in mdx mice. Mol Ther. 2011; 19:1295-1303.

74. Yin H, Moulton HM, Seow Y, Boyd C, Boutilier J, Iverson P, Wood MJ. Cell-penetrating peptide-conjugated antisense oligonucleotides restore systemic muscle and cardiac dystrophin expression and function. Hum Mol
Genet. 2008; 17:3909-3918.

75. Moulton HM, Wu B, Jearawiriyapaisarn N, Sazani P, Lu QL, Kole R. Peptide-morpholino conjugate: a promising therapeutic for Duchenne muscular dystrophy. Ann N Y Acad Sci. 2009; 1175:55-60.

76. Goyenvalle A, Babbs A, Powell D, Kole R, Fletcher S, Wilton SD, Davies KE. Prevention of dystrophic pathology in severely affected dystrophin/utrophindeficient mice by morpholino-oligomer-mediated exonskipping. Mol Ther. 2010; 18:198-205.

77. Crisp A, Yin H, Goyenvalle A, Betts C, Moulton HM, Seow Y, Babbs A, Merritt T, Saleh AF, Gait MJ, Stuckey DJ, Clarke K, Davies KE, Wood MJ. Diaphragm rescue alone prevents heart dysfunction in dystrophic mice. Hum Mol Genet. 2011; 20:413-421.

78. Pandey SN, Lee YC, Yokota T, Chen YW. Morpholino treatment improves muscle function and pathology of Pitxl transgenic mice. Mol Ther. 2014; 22:390-396.

79. Pandey SN, Cabotage J, Shi R, Dixit M, Sutherland M, Liu J, Muger S, Harper SQ, Nagaraju K, Chen YW. Conditional over-expression of PITX1 causes skeletal muscle dystrophy in mice. Biol Open. 2012; 1:629-639.

80. Leidenroth A, Hewitt JE. A family history of DUX4: phylogenetic analysis of DUXA, B, C and Duxbl reveals the ancestral DUX gene. BMC Evol Biol. 2010; 10:3642148-2110-2364.

(Received July 11, 2016; Revised July 29, 2016; Accepted July 30, 2016) 